\title{
Atributos de qualidade do solo sob fitofisionomias de cerrado sensu stricto e cerradão no Parque Nacional das Nascentes do Rio Parnaíba
}

\author{
Tancio Gutier Ailan Costa ${ }^{1}$, Bruna de Freitas Iwata ${ }^{2}$, Juliana \\ Vogado Coelho ${ }^{3}$, Israel Lobato Rocha4, João Gabriel Pereira dos \\ Santos $^{5}$, Nayara Caroline Moreira Leopoldo ${ }^{6}$, Mireia Ferreira \\ Alves7, Ana Carla Ribeiro Maciel6, Gleide Ellen dos Santos \\ Clementino $^{7}$
}

\begin{abstract}
${ }^{1}$ Universidade Federal do Ceará. Mestrado em Ciência do Solo. Campus Pici. Fortaleza-CE (CEP 60455-900). E-mail: gutierailan@gmail.com.

${ }^{2}$ Instituto Federal de Educação, Ciência e Tecnologia do Piauí. Campus Teresina Central. Praça da Liberdade, 1597. Centro. Teresina-PI, Brasil (CEP 64000-040).

${ }^{3}$ Universidade Federal do Paraná. Programa de Pós-Graduação em Ciência do Solo. Rua dos Funcionários, 1540. Juvevê. Curitiba-PR, Brasil (CEP 80035-050).

${ }^{4}$ Instituto Federal de Educação, Ciência e Tecnologia do Piauí. Campus Corrente. Rua Projetada Trinta e Seis, 380. Nova Corrente. Corrente-PI, Brasil (CEP 64980-000).

${ }^{5}$ Instituto Federal do Piauí. Curso de Tecnologia em Gestão Ambiental. Campus Corrente. Rua Projetada Trinta e Seis, 380. Nova Corrente. Corrente-PI, Brasil (CEP 64980-000).

'Instituto Federal de Educação, Ciência e Tecnologia do Piauí. Curso de Pós-Graduação em Estudos Geoambientais e Licenciamento. Campus Corrente. Rua Projetada Trinta e Seis, 380. Nova Corrente. Corrente-PI, Brasil (CEP 64980-000).

${ }^{7}$ Universidade Estadual do Piauí. Curso de Bacharelado em Agronomia. Campus Deputado Jesualdo Cavalcanti. Avenida Joaquina Nogueira de Oliveira, S/№. Aeroporto. Corrente-PI, Brasil (CEP 64980-000).
\end{abstract}

Resumo. A degradação do solo constitui uma das principais ações antrópicas mais preocupante dos últimos tempos, tendo em vista o seu alto poder negativo sobre a vida do homem. Tal problemática resulta do uso inadequado do solo, o que como consequência provoca uma redução drástica da matéria orgânica dos solos, afetando negativamente todas as suas características físicas, químicas e biológicas. Este processo de transformação e uso inadequado do solo abrange grande parte do território brasileiro, no entanto, nas últimas décadas com a abertura de novas áreas agrícolas na Região Central do Brasil, os solos sob vegetação de cerrado foram e têm sido rapidamente incorporados ao processo produtivo culminando na perda irrevogável de algumas características deste ecossistema natural. Neste sentido, o trabalho objetivou avaliar a qualidade do solo medida por indicadores químicos e físicos no Parque Nacional das Nascentes do Rio Parnaíba sob fitofisionomias de Cerrado sensu stricto e

Recebido: $14 / 07 / 2018$

Aceito:

$21 / 08 / 2018$

Publicado:

$31 / 08 / 2018$

Acesso aberto 
Cerradão. Para esta avaliação foram delimitadas duas parcelas de 1 ha sob as duas fitofisionomias do Cerrado (sensu stricto e Cerradão) no Parque Nacional das Nascentes do Rio Parnaíba. Nas duas fitofisionomias foram coletadas amostras de solo nas profundidades de 0,00-0,05 $\mathrm{m}$ e 0,05-0,10 $\mathrm{m}$, buscando avaliar quanto atributo químicos os teores, níveis e concentração de $\mathrm{K}$, $\mathrm{Ca}, \mathrm{P}$ ext, pH, Al, H+Al, NT, COT, Mg, soma de bases, CTC T, CTC t, $\mathrm{V} \%$, como também os percentuais de umidade do solo e seu estado de adensamento sob condições naturais. Para as determinações químicas, as amostras foram secas ao ar, destorroadas e passadas em peneira com malha de $2 \mathrm{~mm}$ e analisadas conforme metodologia específica. As determinações físicas foram realizadas por meio de anel volumétrico para densidade e pesagem e secagem em estufa para umidade do solo. 0 estudo verificou enquanto atributos químicos os solos estudados encontram-se naturalmente ácidos, com baixa disponibilidade de bases trocáveis e reduzida fertilidade natural. Em geral, foram poucas variações significativas quanto características químicas do solo para as fitofisionomias analisadas. Quanto ao atributo físico verificou-se relevante variação para umidade e densidade do solo, sendo a fitofisionomia de Cerradão portadora de maior umidade e sensu stricto maior nível de adensamento natural do solo. Deste modo, destaca-se um equilíbrio dinâmico entre as propriedades químicas e físicas dos solos das fitofisionomias de Cerrado do parque, apresentando qualidade natural típicas das áreas desse bioma.

Palavras-chave: Atributos do solo; Áreas nativas; Fertilidade natural.

\footnotetext{
Abstract. Soil quality attributes under cerrado sensu stricto and cerradão in the Nascentes Rio do Parnaíba National Park. Soil degradation is one of the major anthropogenic actions of recent times, given its negative power over man's life. This problem results in the use of the soil, which results in a drastic reduction of soil organic matter, negatively affecting all its physical, chemical and biological characteristics. This process of transformation and land use of the expansion plan, a large part of the Brazilian space, however, with the last generation of species of agricultural areas in the Central Region of Brazil, the soils under the Cerrado vegetation and the humid ones were quickly incorporated to the productive process culminating in the irrevocable loss of some characteristics of the natural ecosystem. In this sense, the objective of this work was to evaluate soil quality as measured by chemical and physical indicators in the Nascentes do Rio Parnaíba National Park under Cerrado sensu stricto and Cerradão phytophysiognomies. For this evaluation, two 1 ha plots were delineated under two phytophysiognomies of the Cerrado (sensu stricto and Cerradão) in the Nascentes do Rio Parnaíba National Park. In the two phytophysiognomies, soil samples were collected at depths of 0.0-0.05 m and 0.05-0.10 m,
}

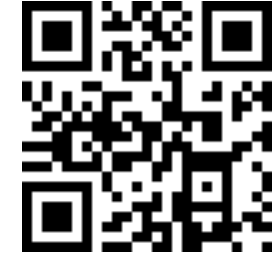

\section{ORCID}

(ㄷ) 0000-0002-0635-2651

Tancio Gutier Ailan

Costa

(1) 0000-0002-6465-9731

Bruna de Freitas Iwata

(1) 0000-0003-2099-9997

Juliana Vogado Coelho

다 0000-0002-4496-9935

Israel Lobato Rocha

(D) 0000-0002-1843-9594

João Gabriel Pereira

dos Santos

(1) 0000-0002-0979-0657

Nayara Caroline

Moreira Leopoldo

(1) 0000-0003-4157-1283

Mireia Ferreira Alves

(1) 0000-0001-8742-4137

Ana Carla Ribeiro

Maciel

(1) 0000-0003-2029-9997

Gleide Ellen dos

Santos Clementino 
aiming to evaluate the chemical attributes of $\mathrm{K}, \mathrm{Ca}, \mathrm{P}$ ext, $\mathrm{pH}, \mathrm{Al}, \mathrm{H}$ $+\mathrm{Al}, \mathrm{NT}, \mathrm{COT}, \mathrm{Mg}$, Base Sum, CTC T, CTC t, V\% as well as the percentages of soil moisture and their state of densification under natural conditions. For the chemical determinations, the samples were air dried, torn and sieved with $2 \mathrm{~mm}$ mesh and analyzed according to specific methodology. The physical determinations were performed by volumetric ring for density and weighing and oven drying for soil moisture. The study verified as chemical attributes the studied soils are naturally acidic, with low availability of exchangeable bases and reduced natural fertility. In general, there were few significant variations in soil chemical characteristics for the analyzed phytophysiognomies. Regarding physical attributes, soil moisture and soil density variation were observed, being the Cerradão phytophysiognomy with higher humidity and sensu stricto higher level of natural soil densification. Thus, a dynamic balance between the physical and chemical properties of the soils of the Park's Cerrado phytophysiognomies, presenting natural quality typical of the areas of this biome, stands out.

Keywords: Soil attributes; Native areas; Natural fertility.

\section{Introdução}

A degradação do solo constitui uma das principais ações antrópicas mais preocupante dos últimos tempos, tendo em vista o seu alto poder negativo sobre a vida do homem (Jakelatis et al., 2008). Tal problemática resulta do uso inadequado do solo, excluindo-se neste caso o manejo conservacionista deste recurso ambiental, o que como consequência provoca uma redução drástica da matéria orgânica dos solos, afetando negativamente todas as suas características físicas, químicas e biológicas.

Esse processo de transformação e uso inadequado do solo, abrange grande parte do território brasileiro, no entanto, nas últimas décadas com a abertura de novas áreas agrícolas na região central do Brasil, os solos sob vegetação de cerrado foram e têm sido rapidamente incorporados ao processo produtivo (Cunha et al., 2001) culminando na perda irrevogável de algumas características desse ecossistema natural. Isso decorre em grande parte da ascensão populacional, crescente demanda por alimento e constante extração de subprodutos dessas áreas em um estreito período de tempo, o que limita a capacidade dessas áreas de se regenerar após sofrem constantes perturbações.

$$
\text { Segundo a Conservation }
$$

International (2005) o bioma Cerrado tem sido a fronteira de expansão agrícola brasileira nos últimos 30 anos, para a produção de soja, milho e, mais recentemente, pecuária. 0 que em decorrência, $37,3 \%$ de sua área se encontram totalmente convertidos para usos antrópicos. Além disso, em 2006 a taxa de conversão de áreas nativas do cerrado para agroecossistemas alcançava a ondem de $12.480 \mathrm{~km}^{2}$ anualmente (Martins Jr e Chaves, 2006) o que atualmente deve-se ter uma representação triplica dessa ordem. 0 grande entrave de todo esse problema decorre do fato de que grande parte das áreas nativas do bioma Cerrado foram convertidas ou transformadas pela ação humana, e isso passou a despertar a necessidade de uma visão mais conservadora para essas áreas.

Com toda essa problemática fica evidente que o solo constitui o principal componente relacionado a produção agropecuária. E por isso a sua 
conservação e melhoria da qualidade é essencial para a sustentação da atividade produtiva (Jakelatis et al., 2008) e dos ecossistemas naturais. Em face disso, sob condições naturais a qualidade edáfica tem sido proposta com o objetivo de se obter um valor padrão ou referência, enquanto em agrossistemas, ela é indicada, com vistas ao manejo do sistema, para incentivar a produção, sem degradar o solo (Gregorich, 2002).

Nestas condições, o grande passo para se garantir a conservação dos solos ou mesmo reduzir a sua degradação é avaliando a sua qualidade e com isso propor práticas conservacionista para os mesmos. Com isso, Doran e Parkin (1994), relatam que é preciso caracterizar os processos e as propriedades do solo que afetam sua capacidade produtiva como forma de avaliar a sua qualidade., mas que para isso é importante identificar e selecionar os indicadores de qualidade física, química e biológica que representem as principais funções do solo.

Para Araújo et al. (2007), algumas características consideradas relativamente simples podem ser usadas para avaliar a qualidade do solo de forma bastante eficaz. Assim, os parâmetros escolhidos para avaliação devem abranger atributos biológicos, químicos e físicos. Além do mais, a determinação das mudanças ocorridas no solo deve ser realizada por conferição das áreas sob ação antrópica com ambientes inalterados, como no caso das florestas por representarem as condições ecológicas de estabilidade do ambiente (Neves Neto et al., 2013).

Neste caso existem alguns atributos que podem ser utilizados para o monitoramento e avaliação dos sistemas de manejo e uso do solo (Larson e Pierce, 1994) e entre eles estão a matéria orgânica do solo ou mesmo o carbono orgânico do solo, densidade do solo e condições hídricas como é o caso da umidade volumétrica, além dos atributos de fertilidade química dos solos, a destaque do $\mathrm{pH}, \mathrm{CTC}$, as bases trocáveis e outros.

Contudo, salienta-se que a compreensão e o monitoramento dos atributos de qualidade dos solos em ambientes inalterados são importantes para se evitar a degradação dos mesmos e proporcionar a manutenção da biodiversidade, principalmente no Bioma Cerrado. Nessa perspectiva, considerando o fato de que boa parte da região circunvizinha do Parque Nacional das Nascentes do Rio Parnaíba tem sofrido influência dos processos produtivos da região, que ao longo do tempo pode causar uma pressão ecológica e degradação ambiental em grande parte da sua área territorial, objetivou-se com este estudo avaliar a qualidade do solo medida por indicadores químicos e físicos no Parque Nacional das Nascentes do Rio Parnaíba sob fitofisionomias de Cerrado sensu stricto e Cerradão.

\section{Material e métodos}

\section{Caracterização da área de estudo}

0 estudo foi desenvolvido no Parque Nacional das Nascentes do Rio Parnaíba (PNNRP), Unidade de Conservação de Proteção Integral, criada por Decreto Federal em 2002, abrangendo uma área de 729.813 ha e parte do topo das Chapadas das Mangabeiras e suas encostas. O PNNRP está localizado no divisor das Bacias Hidrográficas dos Rios São Francisco, Tocantins e Parnaíba e compreende os domínios do Bioma Cerrado entre a Região Sul do Piauí e Maranhão, norte do Tocantins e noroeste da Bahia (Lima, 2009). Com sua expressiva extensão territorial, a maior parte de sua área está localizado no Estado do Piauí cobrindo os Municípios de Gilbués, São Gonçalo do Gurguéia, Barreiras do Piauí e Corrente, além dos Municípios de Formosa do Rio Preto na Bahia, Mateiro, São Félix e Lizarda no Tocantins e Alto do Parnaíba no Maranhão (Figura 1). 

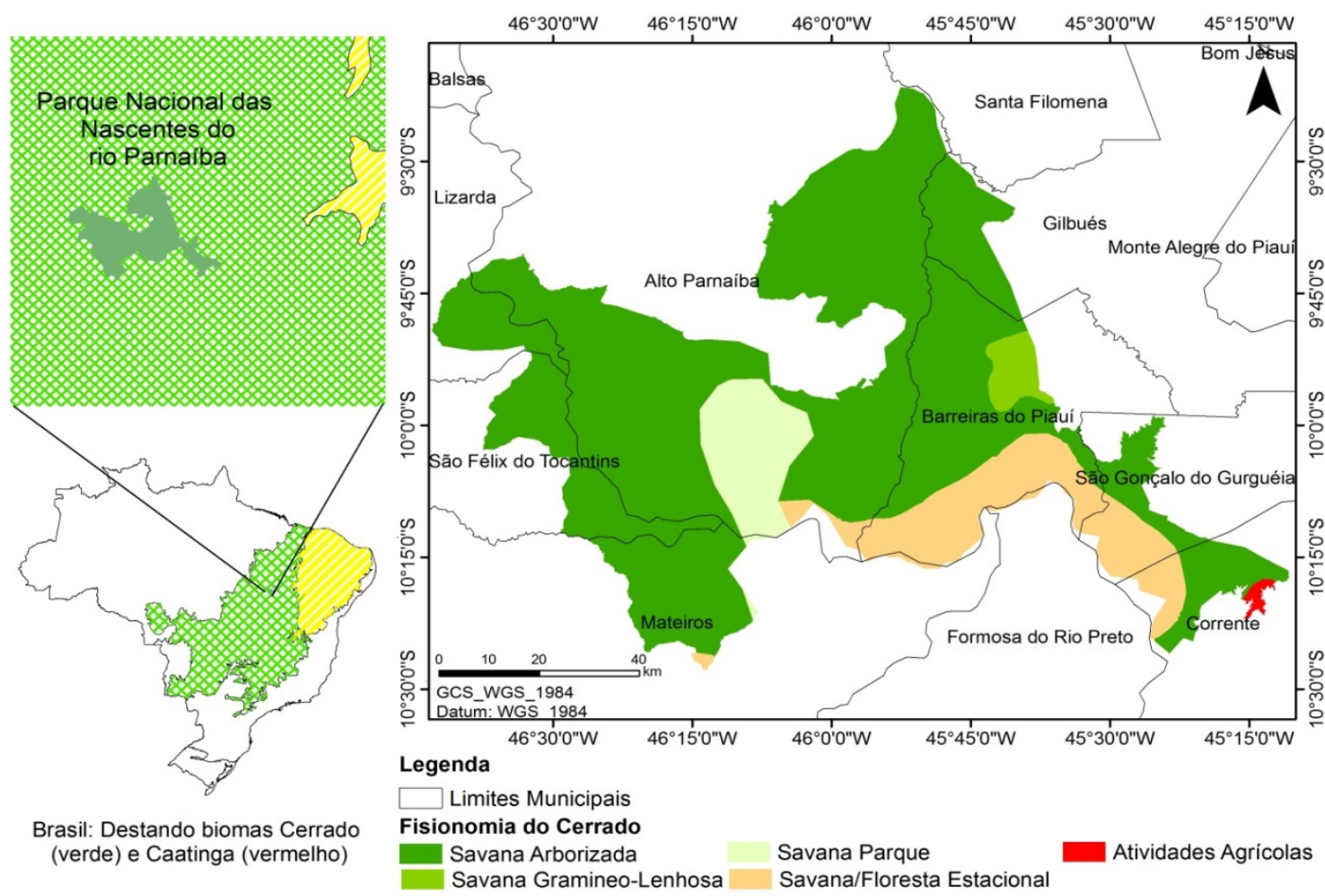

Figura 1. Localização geográfica do Parque Nacional das Nascentes do Rio Parnaíba. Elaborado por Cristian Epifânio de Toledo, 2017.

Dada sua localização na porção centro-ocidental do Nordeste brasileiro, o estudo foi realizado na porção piauiense do PNNRP, especificamente em área correspondente ao Município de Barreiras do Piauí.

\section{Vegetação}

O PNNRP está inserido na região que apresenta a maior extensão de cobertura vegetal natural do Bioma Cerrado, possuindo uma vegetação complexa e diversificada. Machado et al. (2004) afirma que o parque apresenta tipos fisionômicos pertencentes ao bioma, nelas incluindo a fitofisionomia de campo-cerrado, cerrado típico ou sensu stricto e brejo ou veredas, sendo a primeira característica do platô das chapadas. Além destas, Santos (2001) reconheceu mais duas fitofisionomias nas porções do parque, sendo elas o Cerrado Campo Limpo e Cerradão.

\section{Relevo}

Segundo o MMA (2007) as partes terminais da chapada apresentam perfis irregulares e sinuosos, formando escarpas bem definidas na parte superior, com paredões e perfis verticalizados e em sua maioria desprovidos de cobertura vegetal. A depressão subsequente desenvolve-se abaixo dos rebordos festonados, em nível médio aproximado de $400 \mathrm{~m}$ a $800 \mathrm{~m}$. A área tem importância fundamental por tratar-se das nascentes obsequentes que tendem a promover, por erosão regressiva, o recuo da escarpa e dos rebordos da chapada. Possuí veredas que são planícies fluviais de acumulação inundáveis, constituídas por sedimentos holocênicos de textura predominantemente arenosa, estabelecidas a uma altitude média aproximada de 20 a $30 \mathrm{~m}$ 
de rebordo da chapada, assim originando numerosos córregos.

\section{Solo}

Os solos nestas chapadas são profundos e de baixa fertilidade natural e nos declives das vertentes apresentam-se arenosos rasos e pobres, com a presença de afloramentos rochosos e com alta permeabilidade (FURPA, 2000). As principais associações ou classes de solos dominantes são: Latossolos vermelhosamarelos; solos litólicos + pdzólicos vemelho-amarelos concrecionários + afloramentos rochosos; latossolos vermelho-amarelos + neossolos quartzarênicos + podzólicos acinzentados + neossolos quartzarênicos hidromóficas; neossolos quartzarênicos + neossolos aluviais (MMA, 2007).

\section{Geologia}

A região do PNNRP do ponto de vista geológico estrutural, integra a Bacia Sedimentar do Maranhão-Piauí e a Bacia Sanfranciscana. Na área das nascentes predomina a Formação Sambaíba ou Balsas de idade triássica e subjacente à Formação Urucuia. É constituída de arenitos, róseos, avermelhados, amarelados e brancos de granulometria fina a média. Sua maior extensão encontra-se no estado da Bahia. No Piauí, Maranhão e Tocantins, representa o topo da Chapada das Mangabeiras sendo denominada de Formação Urucuia (MMA, 2007).

\section{Hidrologia}

As chuvas, como fonte de suprimento, tendem a modificar de modo temporário a água disponível em superfície, no solo e no subsolo. As condições geomorfológicas influenciam através das características dos compartimentos do relevo com repercussões nos perfis longitudinais dos rios e nos seus respectivos vales. $\mathrm{Na}$ Chapada das Mangabeiras recoberta por arenitos da Formação Urucuia a excessiva permeabilidade dos terrenos impede a concentração de água em superfície, toda a água precipitada tende a percolar até ressurgir na base do escarpamento como fontes perenes que formam as nascentes fluviais. Quanto às águas subterrâneas, as águas profundas, a exemplo do que se verifica na Chapada das Mangabeiras e na depressão subsequente, correspondem respectivamente aos aquíferos Urucuia e Sambaíba e as águas subterrâneas próximas à superfície do solo, deve-se considerar os aquíferos das veredas em sedimentos de neoformação (MMA, 2007).

\section{Clima}

Quanto às chuvas, a região apresenta duas estações climáticas bem definidas, característica das regiões tropicais, correspondente a um período seco, que vai de maio a novembro e outro chuvoso, que vai de dezembro a abril, aproximadamente. Por outro lado, estas chuvas apresentam uma alta variabilidade interanual típica das regiões semiáridas. 0 ciclo das chuvas é regulado pelas massas: Equatorial Atlântica (Ea), Equatorial Continental (Ec), Tropical Atlântica (Ta), e a Zona de Convergência Intertropical (ZCIT). Conforme classificação Köppen-Geiger o clima é caracterizado como quente e úmido do tipo Aw, temperatura média anual de $26{ }^{\circ} \mathrm{C}$ e totais pluviométricos anuais em torno de 750 a $1.400 \mathrm{~mm}$ (MMA, 2007). Na Figura 2 está registrado o comportamento pluviométrico da região no período de realização do estudo. 


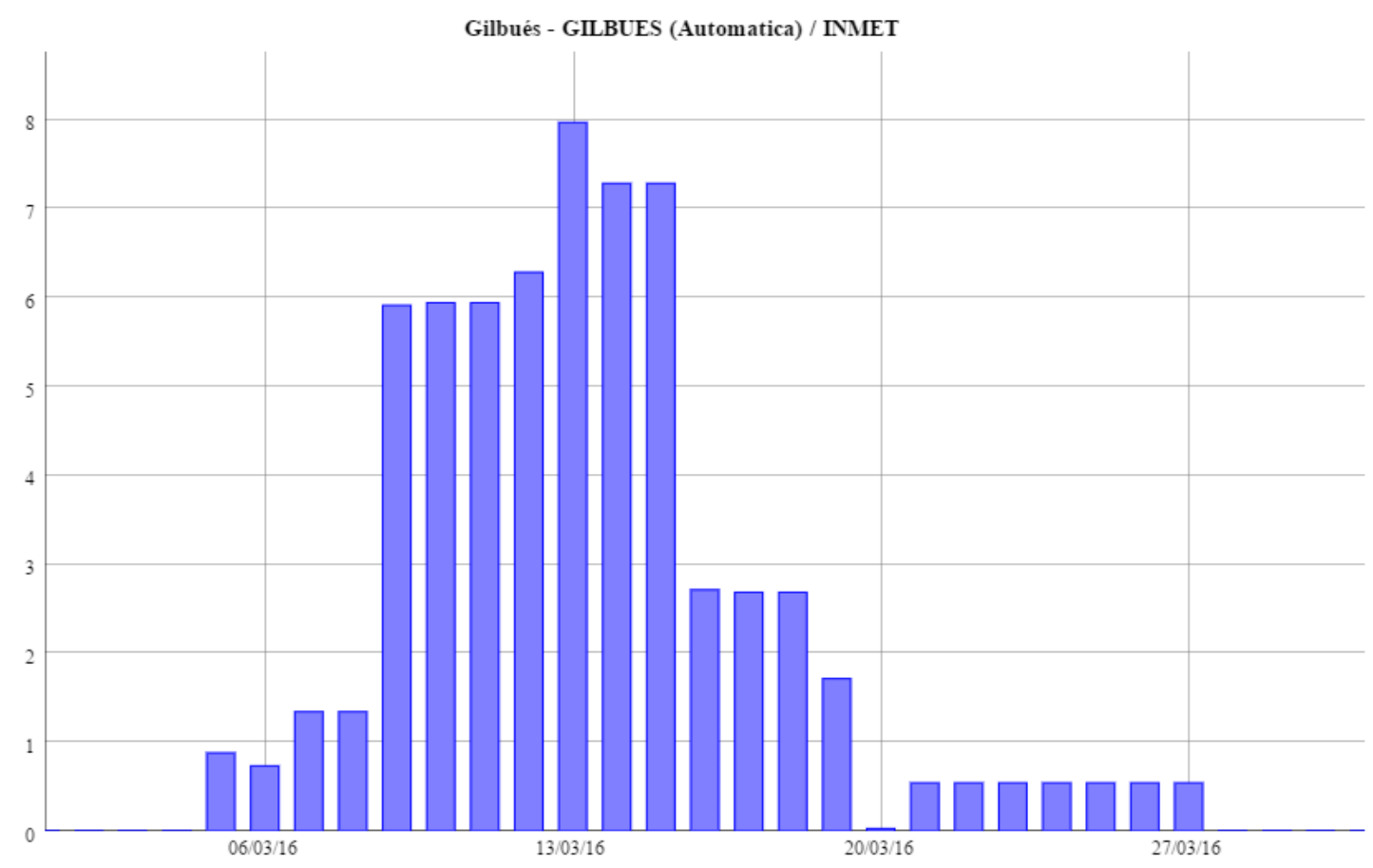

Precipitação

Figura 2. Precipitação mensal (mm) durante o período de estudo. Fonte: INMET (2017).

\section{Descrição das fitofisionomias amostradas \\ No estudo foram amostradas duas importantes fitofisionomias do PARNA e do referido bioma: a fitofisionomia de Cerrado sensu stricto e de Cerradão. A caracterização das fitofisionomias está descrita abaixo, segundo dados de Oliveira (2004):}

Cerrado sensu stricto: para esse tipo fisionômico a vegetação é caracterizada pela presença de dois estratos, sendo um herbáceosubarbustivo com predominância de gramíneas e outro arbustivo-arbóreo com cobertura arbórea de $10 \%$ a $60 \%$. 0 estrato arbustivo-arbóreo caracteriza-se pela presença de plantas com aproximadamente $5 \mathrm{~m}$ apresentando tortuosidade dos ramos, ramificação irregular, ritidoma esfoliado corticoso rígido e casca suberosa macia (Figura 3). 

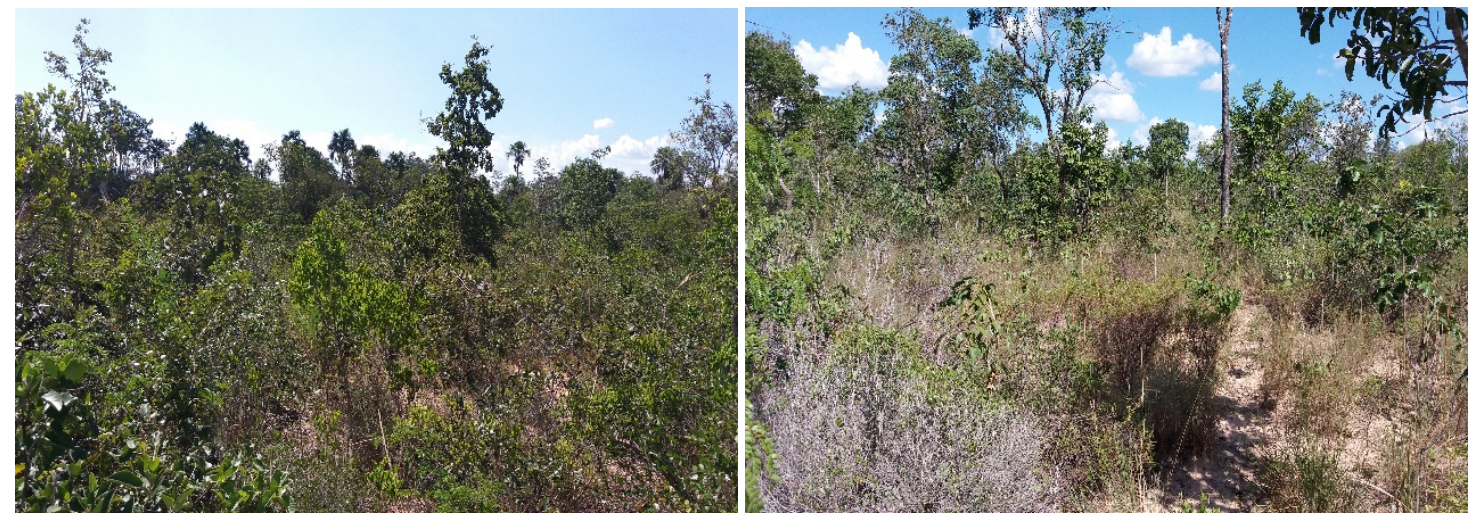

Figura 3. Aspecto fisionômico de cerrado sensu stricto no PNNRP. Fonte: Autores, 2016.
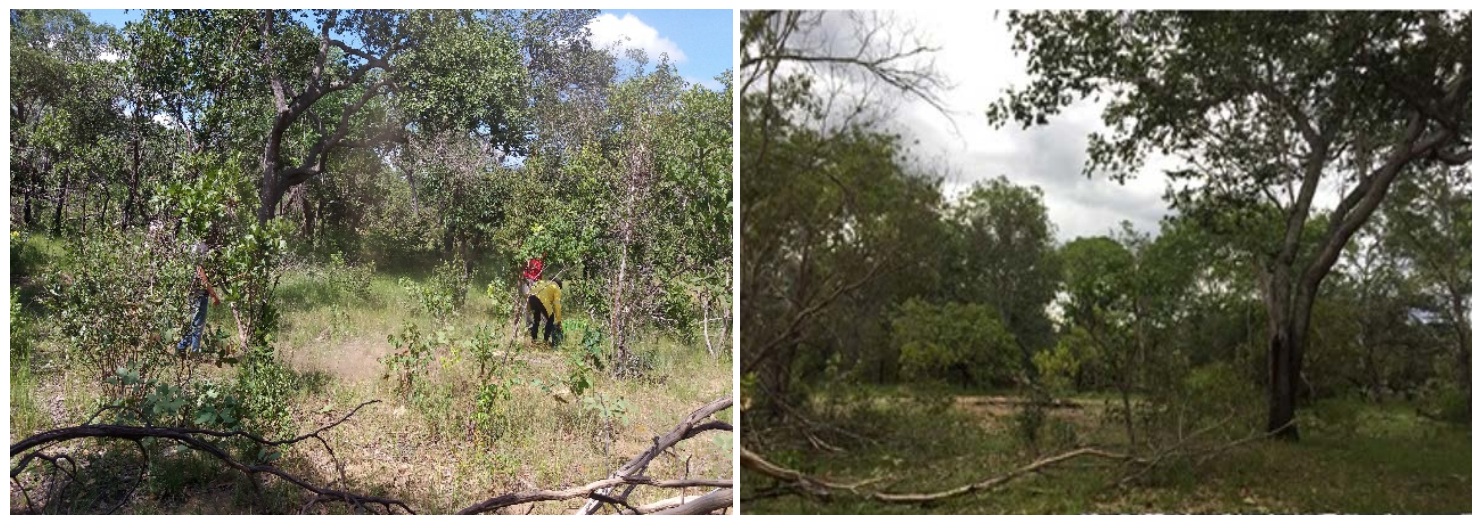

Figura 4. Aspecto fisionômico de Cerradão no PNNRP. Fonte: Autores, 2016.

Cerradão: Semelhante ao cerrado típico, sua fisionomia apresenta dois estratos, sendo o herbáceosubarbustivo bastante escasso (Figura 4). Nessa fitofisionomia predominam árvores altas e retas com altura de até $7 \mathrm{~m}$ e troncos de casca fina, lisa ou às vezes rugosa, com presença de lenticelas, ou ainda esfoliastes.

\section{Procedimentos metodológicos}

A determinação dos atributos de qualidade do solo foi realizada em área composta por dois tratamentos referentes à fitogeografia do bioma Cerrado: fisionomia de Cerradão (CE) e fisionomia sensu stricto (SS). 0 delineamento amostral corresponde a duas parcelas de 1 ha para cada um tratamento amostral (Figura 5). As parcelas de 1 ha foram subdivididas em 5 sub-parcelas correspondente a 0,2 ha.

Em cada sub-parcelas (0,2 ha) delimitada conforme fitogeografias do Cerrado foram realizadas coletas de solo referente ao período de março de 2016. Nestas, foram selecionados de forma aleatória dez pontos amostrais a uma distância média de $10 \mathrm{~m}$ uns dos outros. Em cada ponto foram coletadas duas amostras de solo em profundidades diferentes variando entre 0,0-0,05 m e 0,05-0,10 m e 0,00-0,10 m no solo. 


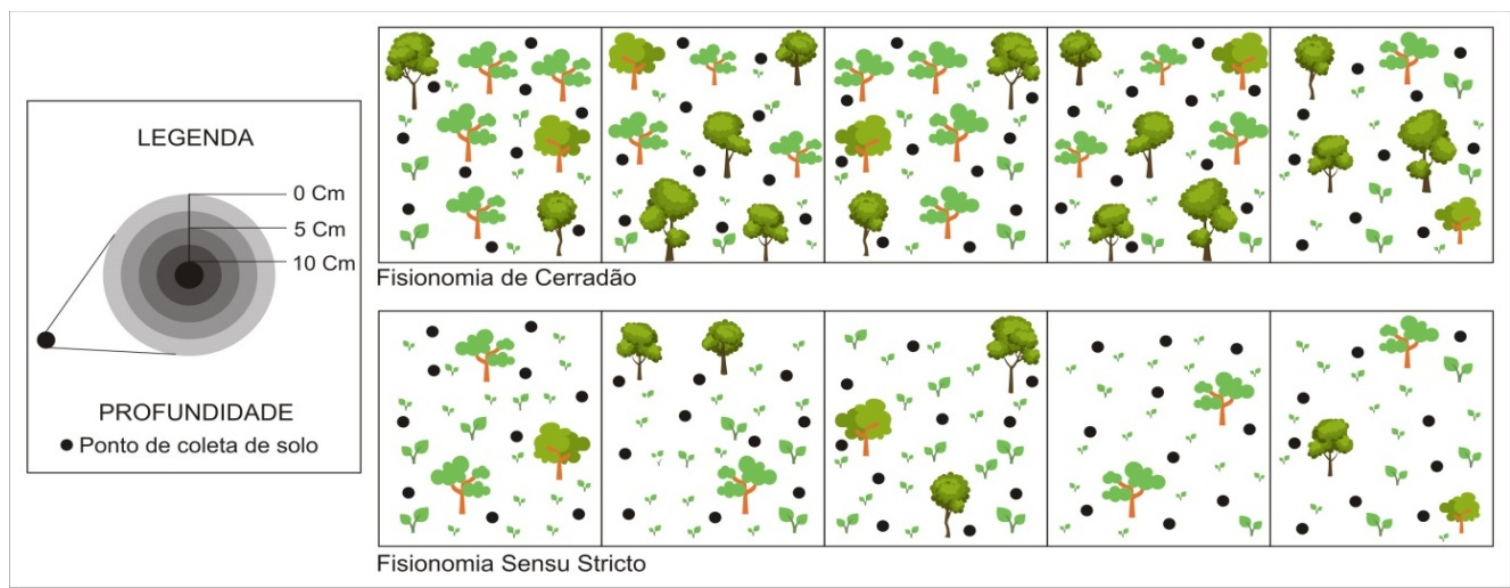

Figura 5. Representação esquemática do sistema de coleta do solo em centímetros adotado no estudo. Fonte: Autores, 2017.

Para determinação dos atributos químicos do solo, foram coletadas amostras de solo nas profundidades de 0,0-5 $\mathrm{m}$ e 0,05-0,10 $\mathrm{m}$ com estrutura deformada, com auxílio de trado do tipo holandês. As amostras foram acondicionadas e encaminhadas para avaliação em laboratório. $\mathrm{Na}$ caracterização química dos solos estudados, foram determinados os teores de $\mathrm{K}, \mathrm{Ca}, \mathrm{P}$ ext, $\mathrm{pH}, \mathrm{Al}, \mathrm{H}+\mathrm{Al}, \mathrm{NT}$, COT, Mg, Soma de bases, CTC T, CTC $t, V \%$. Para as determinações químicas, as amostras foram secas ao ar, destorroadas e passadas em peneira com malha de $2 \mathrm{~mm}$.

Determinaram-se o $\mathrm{pH}$ do solo em água $(1: 2,5)$ por potenciometria, a acidez trocável $\left(\mathrm{Al}^{+3}\right)$ extraída com $\mathrm{KCl}$ 1 mol.L $\mathrm{L}^{-1}$ e quantificada por titulometria com hidróxido de sódio 0,025 mol. $\mathrm{L}^{-1}$ padronizado com biftalato de potássio (EMBRAPA, 1997). O fósforo e o potássio foram extraídos com Mehlich l e determinados por calorimetria e fotometria de chama, respectivamente. A determinação do cálcio e o magnésio foi por espectrofotometria de absorção atômica, extraídos com $\mathrm{KCl}$ mol. $\mathrm{L}^{-1}$. O Nitrogênio total (NT) do solo foi determinado por meio da digestão sulfúrica e dosado por destilação Kjedhal (Bremner et al., 1982). O carbono orgânico total foi quantificado a partir da oxidação da matéria orgânica via úmida com dicromato de potássio, em presença de $\mathrm{H}_{2} \mathrm{SO}_{4}$ e aquecimento externo, titulando-se o excesso de dicromato com sulfato ferroso amoniacal (Yeomans e Bremner, 1988).

Os atributos físicos do solo, foram determinados com base na coleta de amostras de solo com estrutura indeformada para densidade volumétrica e deformada para umidade volumétrica, nas profundidades de $0.00-0.10 \mathrm{~m} \mathrm{e}$ 0.0-5 m e 0.05-0.10 m respectivamente. A densidade do solo (g.cm $\left.{ }^{-3}\right)$ foi determinada pelo método do anel volumétrico (Uhland), com $7 \mathrm{~cm}$ de altura por $5 \mathrm{~cm}$ de diâmetro e volume conhecido e a umidade volumétrica do solo (\%) foi determinada com base na diferença de massa, ambas conforme a metodologia proposta pela EMBRAPA (1997).

Como tratamento amostral, os dados foram submetidos à comparação das médias dos atributos de qualidade do solo, realizados por meio do teste de Tukey a 5\%, utilizando o pacote estatístico ASSISTAT 7.7. 


\section{Resultados e discussão}

\section{Atributos químicos de qualidade do solo \\ Em relação aos níveis de acidez} do solo, o estudo verificou que os valores de $\mathrm{pH}$ juntamente com o alumínio trocável $\left(\mathrm{Al}^{3+}\right)$ e acidez potencial $\left(\mathrm{H}^{+} \mathrm{Al}\right)$ não diferiram estatisticamente, tanto em relação aos tratamentos estudados quanto em relação as profundidades. $\mathrm{Na}$
Tabela 4, é possível verificar que os solos das fitofisionomias estudadas, apresentaram-se naturalmente ácidos, resultados típicos de solos do Cerrado. Este fato condiz com o que apontam Lopes e Cox (1977), pois os mesmos verificaram que os solos do Cerrado são de forma natural, ácidos, descrição que os adapta principalmente aos Latossolos, responsáveis por cobrir metade da área total do Cerrado.

Tabela 1. Nível de acidez do solo sob diferentes fitofisionomias do bioma Cerrado no PNNRP.

\begin{tabular}{|c|c|c|c|}
\hline \multirow{2}{*}{ Tratamento } & $\mathbf{p H}$ & $\mathbf{A l}^{3+}$ & $\mathbf{H}^{+} \mathbf{A l}$ \\
\hline & \multicolumn{3}{|c|}{$\mathrm{cmol}_{\mathrm{c}} / \mathrm{kg}$} \\
\hline \multicolumn{4}{|c|}{------------------------------0.00 - 0.05 m----------------------------- } \\
\hline CE & $4,89 a^{*}$ & $0,20 \mathrm{a}$ & $0,84 \mathrm{a}$ \\
\hline SS & $4,72 \mathrm{a}$ & $0,23 \mathrm{a}$ & $1,00 \mathrm{a}$ \\
\hline \multicolumn{4}{|c|}{ - } \\
\hline CE & $4,70 \mathrm{a}$ & $0,19 \mathrm{a}$ & $0,89 \mathrm{a}$ \\
\hline SE & $4,77 \mathrm{a}$ & $0,24 \mathrm{a}$ & $0,75 \mathrm{a}$ \\
\hline
\end{tabular}

CE - Cerradão; SS - Sensu stricto; pH - Potencial hidorgeniônico; $\mathrm{Al}^{3+}$ - Alumínio trocável; $\mathrm{H}^{+} \mathrm{Al}$ Acidez potencial. *As médias seguidas pela mesma letra não diferem estatisticamente entre si pelo Teste de Tukey ao nível de $5 \%$ de probabilidade.

Conforme a Tabela 4 o pH do solo apresentou valores correlatos aos valores de $\mathrm{Al}^{+3} \mathrm{e} \mathrm{H}^{+} \mathrm{Al}$ em ambos os tratamentos. Isso ocorre pela relação que estes atributos possuem no solo exercendo influência uns sobre os outros, no qual a redução proporcional dos níveis de $\mathrm{Al}^{+3} \mathrm{e}$ $\mathrm{H}^{+} \mathrm{Al}$ tendem a contribuir com o aumento dos valores de $\mathrm{pH}$ nos solos.

Os valores semelhantes dos atributos de acidez do solo nas áreas estudadas podem estar relacionados com o comportamento similar do aporte cíclico da biomassa aérea e radicular nos solos destas áreas, podendo estar atuando igualmente na manutenção da acidez do solo. Logo, aportando quantidades de nutrientes que se equilibram com as perdas pelos processos de nutrição, assim como perdas por lixiviação, mesmo com diferentes estratos de vegetação.
Segundo Teodoro (2014) o comportamento das raízes finas e grossas em áreas de vegetação natural contribuem para o maior aporte de biomassa radicular que fica estocada no solo do Cerrado, podendo contribuir para a ciclagem de nutrientes nesse compartimento.

As perdas de nutrientes pelo processo de lixiviação natural concorrem significativamente com a manutenção dos teores de hidrogênio e alumínio, influenciando os processos de redução do $\mathrm{pH}$ e consequentemente aumentando os níveis de acidez natural dos solos. Kolm (2001) aponta que dentre as principais formas de saídas de nutrientes dos ecossistemas terrestres, pode-se citar o processo de lixiviação, o que contribui para a perda destes e por vezes a redução da fertilidade natural dos solos. 
0 resultado das bases trocáveis do solo, apresentados na Tabela 5, demonstram valores relativamente baixos de $\mathrm{K}^{+}, \mathrm{Ca}^{2+}, \mathrm{Mg}^{2+}$, típicos de solos de cerrado, em que na maioria das vezes se apresentam como solos de baixa fertilidade natural, mesmo estando em áreas sob floresta nativa.

Tabela 1. Bases trocáveis do solo sob duas fitofisionomias do bioma Cerrado no PNNRP.

\begin{tabular}{|c|c|c|c|}
\hline \multirow{2}{*}{ Tratamento } & $\mathbf{K}^{+}$ & $\mathrm{Ca}^{2+}$ & $\mathrm{Mg}^{2+}$ \\
\hline & \multicolumn{3}{|c|}{$\mathrm{cmol}_{\mathrm{c}} / \mathrm{kg}$} \\
\hline \multicolumn{4}{|c|}{ 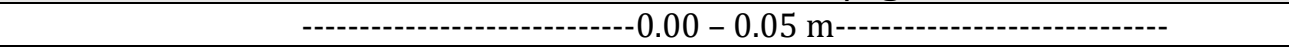 } \\
\hline CE & $0,21 a^{*}$ & $3,41 \mathrm{a}$ & $1,18 \mathrm{a}$ \\
\hline SS & $0,02 \mathrm{~b}$ & $2,51 \mathrm{~b}$ & $1,34 \mathrm{a}$ \\
\hline \multicolumn{4}{|c|}{-----------------------------0.05 - 0.10 m----------------------------- } \\
\hline $\mathbf{C E}$ & $0,15 \mathrm{a}$ & $2,97 \mathrm{a}$ & $1,19 \mathrm{~b}$ \\
\hline SS & $0,02 \mathrm{~b}$ & $1,97 \mathrm{a}$ & $1,66 \mathrm{a}$ \\
\hline
\end{tabular}

CE - Cerradão; SS - Sensu stricto; K - Potássio; Ca - Cálcio; Mg - Magnésio. *As médias seguidas pela mesma letra não diferem estatisticamente entre si pelo Teste de Tukey ao nível de 5\% de probabilidade.

Em geral, os baixos valores de $\mathrm{K}^{+}$, $\mathrm{Ca}^{2+}, \mathrm{Mg}^{2+}$ podem estar relacionados com o potencial de equilíbrio da ciclagem de nutriente em ambas as áreas, apresentando-se como um sistema autossuficiente na ciclagem natural dos elementos presentes nos solos das fitofisionomias em questão. Embora muitas vezes esperem-se elevados valores quanto às bases trocáveis em solos sob vegetação nativa, os mesmos podem se apresentar relativamente baixos, conforme os resultados obtidos no estudo, o que em muitos casos se configura como um processo de auto ciclagem de elementos naturais do solo em áreas nativas reduzindo a disponibilidade de $\mathrm{K}^{+}, \mathrm{Ca}^{2+}, \mathrm{Mg}^{2+}$ e por ventura a fertilidade do solo em contexto natural. Conforme Cardoso et al. (2009) solos sob áreas de formações florestais nativas apresentam baixa fertilidade natural e têm sua manutenção fortemente associada ao equilíbrio entre a cobertura vegetal e os processos biogeoquímicos realizados no solo.

Além disso, solos com maior nível de acidez tendem a reduzir a disponibilidade das bases trocáveis, principalmente para o bioma Cerrado. Neste contexto, Ramos et al. (2009) afirmam que os processos de acidificação influenciam caracteristicamente nas perdas de cálcio, magnésio e potássio.

Quanto à riqueza de nutriente, é possível verificar através da Tabela 6 , que os solos das fitofisionomias estudadas apresentam-se relativamente com baixa disponibilidade de nutrientes, apresentando variações tanto por tratamento quanto por profundidade. No geral, essa baixa disponibilidade de nutriente é refletida pela reduzida existência dos atributos trocáveis no solo $\left(\mathrm{K}^{+}, \mathrm{Ca}^{2+}, \mathrm{Mg}^{2+}\right)$, que são responsáveis por determinar tais riquezas.

Provavelmente, os resultados obtidos quanto à riqueza de nutrientes estão relacionados com as características típicas dos solos de Cerrado, que são normalmente velhos e bem intemperizados e conforme períodos de precipitação concentrados da região são fortemente influenciados por ações do intemperismo químico e o relevo suavemente ondulado nestas áreas, sendo importantes contribuintes para a elevada taxa de lixiviação natural dos 
nutrientes do solo influenciando a sua qualidade química. Segundo Côrrea Neto et al. (2007) os solos de Cerrado especificamente em áreas nativas, principalmente os Latossolos ou
Argissolos, apresentam altas taxas de lixiviação de nutrientes, visto que são menos suscetíveis à erosão hídrica em função do relevo plano à suave ondulado.

Tabela 3. Riqueza de nutrientes do solo sob duas fitofisionomias do bioma Cerrado no PNNRP.

\begin{tabular}{|c|c|c|c|c|c|}
\hline \multirow{2}{*}{$\begin{array}{c}\text { Tratament } \\
\text { o }\end{array}$} & SB* & CTC T & CTC t & $\mathbf{V}$ & $\mathbf{M}$ \\
\hline & \multicolumn{3}{|c|}{$\mathrm{cmol}_{\mathrm{c}} / \mathbf{k g}$} & \multicolumn{2}{|c|}{$\%$} \\
\hline \multicolumn{6}{|c|}{ 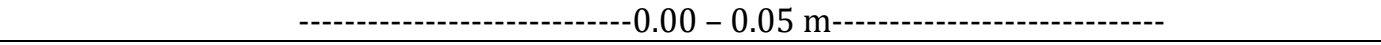 } \\
\hline $\mathbf{C E}$ & $4,81 \mathrm{a}^{*}$ & $5,66 \mathrm{a}$ & $5,01 \mathrm{a}$ & $85,11 \mathrm{a}$ & $4,02 \mathrm{a}$ \\
\hline SS & $3,90 \mathrm{~b}$ & $4,90 \mathrm{a}$ & $4,13 \mathrm{a}$ & $80,08 \mathrm{a}$ & $5,84 \mathrm{a}$ \\
\hline \multicolumn{6}{|c|}{ 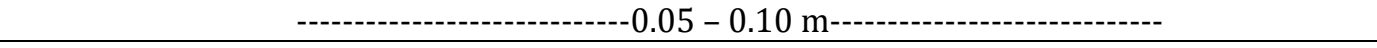 } \\
\hline CE & $4,31 \mathrm{a}$ & $5,20 \mathrm{a}$ & $4,51 \mathrm{a}$ & $82,63 \mathrm{a}$ & $4,56 \mathrm{~b}$ \\
\hline SS & $3,65 \mathrm{~b}$ & $4,40 \mathrm{a}$ & $3,89 \mathrm{a}$ & $83,40 \mathrm{a}$ & $6,28 \mathrm{a}$ \\
\hline
\end{tabular}

CE - Cerradão; SS - Sensu stricto; SB - Soma de bases; CTC T - Capacidade de toca de cátions potencial; CTC t - Capacidade de toca de cátions efetiva; V - saturação por bases; $\mathrm{m}$ - Saturação por alumínio. *As médias seguidas pela mesma letra não diferem estatisticamente entre si pelo Teste de Tukey ao nível de $5 \%$ de probabilidade.

Em se tratando das variações quanto tratamento e profundidade, observou-se que os valores de SB, CTC T e CTC $t$, foram relativamente superiores na área sob fitofisionomia de Cerradão quando comparado aos valores obtidos em áreas sob Cerrado Sensu Stricto. Isso pode ter relação direta com um maior aporte de matéria orgânica sob os solos de fitofisionomia de Cerradão, uma vez que os mesmos podem dispor de uma maior deposição de serapilheira sobre o solo, contribuindo para a elevação nos teores de matéria orgânica sobre este, e consequentemente regulando a disponibilidade natural de nutrientes.

Có Júnior (2011) afirma que a CTC é uma das variáveis que interferem na fertilidade do solo, decorrente em função da mineralogia dos solos e dos níveis de matéria orgânica disponíveis, tendo em vista que essas partículas apresentam cargas elétricas superficiais que variam em função do $\mathrm{pH}$, e contribuem para a CTC do solo, especialmente de solos tropicais, tipicamente intemperizados. Além disso, o mesmo destaca que a CTC no solo apresenta maiores valores na camada superficial, sendo reduzida com o aumento da profundidade, como observado na Tabela 6.

Conforme observado no estudo à saturação por base (V\%) apresentou valores significativamente alto para as duas fitofisionomias não sofrendo diferenciação estatística (Tabela 6). Kiehl (1979) relata que valores elevados de V\% representam solo com alta concentração de nutrientes e reduzido nível de acidez atingindo valores próximos a neutralidade, fator contraditório aos resultados obtidos em solos de Cerrado. Assim, os resultados identificados podem se relacionar com o fato de ambas fitofisionomias apresentarem um forte aporte de material orgânico depositado sob as camadas mais superficiais do solo, influenciando a elevação do V\% nestas áreas, apesar destes solos serem relativamente pobres, e com valores relativamente estáveis para a saturação por alumínio como visto na Tabela 6 .

Os atributos orgânicos do solo sob as fitofisionomias estudadas mostram-se relativamente altos, 
denotando um maior equilíbrio no aporte de material orgânico nestas áreas, influenciando a sua qualidade natural. $\mathrm{Na}$ Tabela 7, pode-se verificar elevados teores de Carbono orgânico total (COT) do solo, não diferindo quanto às áreas estudas em termos estatísticos.

Tabela 4. Material orgânico sob diferentes fitofisionomias do bioma Cerrado no PNNRP.

\begin{tabular}{|c|c|c|c|}
\hline \multirow{2}{*}{ Tratamento } & COT & NT & P ext \\
\hline & g/kg & g/kg & $\mathbf{m g} / \mathbf{k g}$ \\
\hline \multicolumn{4}{|c|}{ - } \\
\hline CE & $48,88 a^{*}$ & $321,60 \mathrm{a}$ & $8,26 \mathrm{a}$ \\
\hline SS & $47,22 \mathrm{a}$ & $284,00 \mathrm{~b}$ & $1,03 \mathrm{~b}$ \\
\hline \multicolumn{4}{|c|}{ - } \\
\hline CE & $47,00 \mathrm{a}$ & $332,60 \mathrm{a}$ & $5,92 \mathrm{a}$ \\
\hline SS & $47,78 \mathrm{a}$ & $243,60 \mathrm{~b}$ & $1,05 \mathrm{~b}$ \\
\hline
\end{tabular}

CE - Cerradão; SS - Sensu stricto; COT - Carbono Orgânico Total; NT - Nitrogênio; P ext - Fosforo total *As médias seguidas pela mesma letra não diferem estatisticamente entre si pelo Teste de Tukey ao nível de $5 \%$ de probabilidade.

Os valores expressivos de COT devem estar relacionados com a deposição considerável de serapilheira sobre as áreas, em que os processos naturais de decomposição em áreas sob vegetação nativas, contribuem para um melhor aporte matéria orgânica sobre o solo, influenciando os teores de COT e que por vez também exerce influência sobre diversas funções do solo, considerando a ciclagem de nutrientes e fertilidade deste. Para Lovato et al. (2004) o COT é um dos atributos do solo que possivelmente apresenta melhor interação com propriedades que coordenam diferentes funções no solo, tais como a ciclagem de nutrientes e consequentemente a fertilidades do solo, entre outros. Quanto ao NT e o P ext pode-se verificar que os maiores teores acometeram áreas sob fitofisionomia de cerradão podendo ter relação com uma menor taxa de decomposição da matéria orgânica, relacionada possivelmente com a baixa ação da microbiota decompositora e temperaturas menos elevadas no solo. Segundo Aerts (1997) condições de baixas temperaturas e períodos de estiagem influenciam diretamente o metabolismo da microbiota do solo, reduzindo as suas atividades e consequentemente diminuindo a intensidade dos processos de decomposição.

\section{Atributos físicos de qualidade do solo}

Os atributos físicos do solo, tais como densidade e umidade são importantes indicadores da qualidade do solo (Carvalho et al., 2007) exercendo grande influência sobre a sua produtividade e a qualidade ambiental. Além de influenciar os processos químicos e biológicos do solo, sendo fundamental na manutenção da qualidade dos mesmos (Streck, 2007). 


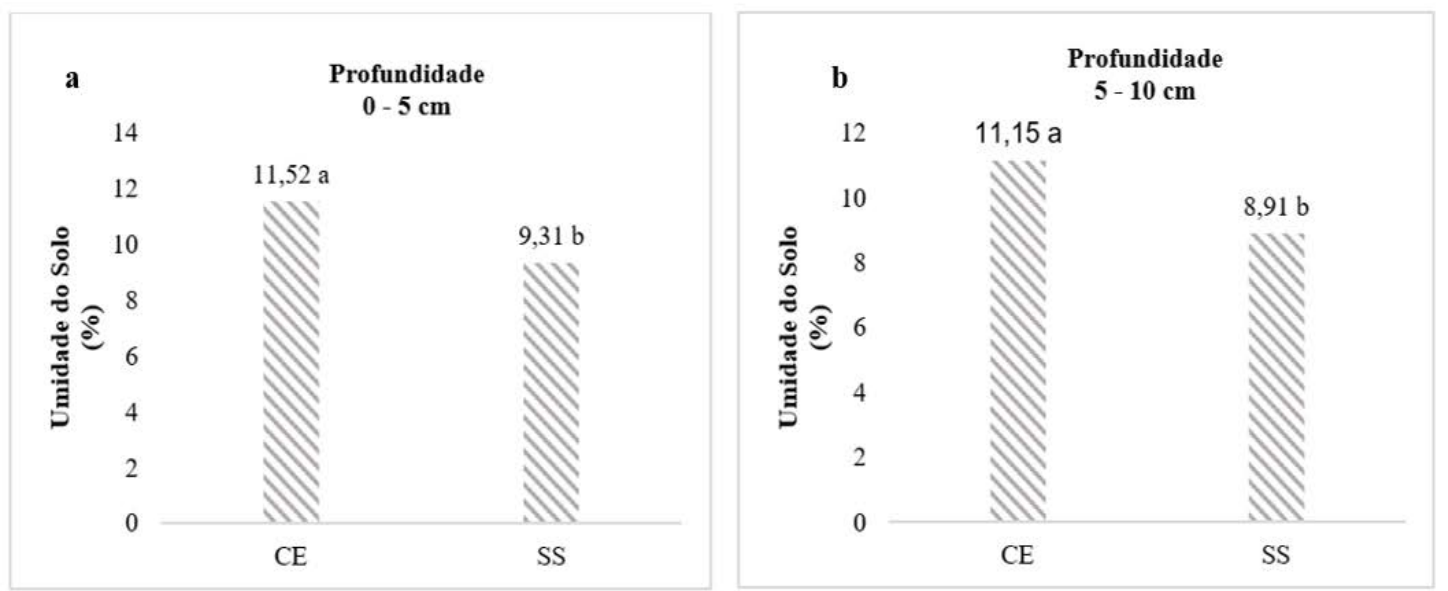

Figura 6. Percentual de umidade do solo sob diferentes fitofisionomias do Cerrado no PNNRP: a umidade do solo em profundidade de 0.00-0.05 m e b - umidade do solo de 0.05-0.10 m de profundidade. CE - Cerradão; SS - Sensu Stricto. * As médias seguidas pela mesma letra não diferem estatisticamente entre si pelo Teste de Tukey ao nível de $5 \%$ de probabilidade.

Neste contexto, em relação aos atributos físicos do solo sobre os tratamentos estudados, verificou-se que a área sob fitofisionomia de Cerradão apresentou os maiores percentuais de umidade do solo quando comparada ao Cerrado sensu stricto, variando estatisticamente tanto em profundidade quanto fitofisionomia (Figura 6).

Conforme a Figura 6, os maiores valores de umidade na fitofisionomia de CE podem estar relacionados ao fato desta fitofisionomia apresentar maior deposição de serapilheira e consequentemente uma maior concentração dos níveis de matéria orgânica na superfície do solo, contribuindo para uma maior retenção de água ao longo do perfil do solo, além de equilibrar ainda mais a concentração de matéria orgânica em relação às perdas (output) nestas áreas. Assim, a matéria orgânica aumenta a capacidade de infiltração de água no solo e a sua capacidade de armazenamento devido à melhoria das condições físicas dos horizontes superficiais, principalmente em relação a sua estrutura (Tate, 1992).

Quanto ao adensamento natural do solo o estudo verificou que na área sob fitofisionomia SS ocorreu um maior valor de densidade, quando associado ao resultado encontrado em áreas sob fitofisionomias de CE (Figura 7), variando estatisticamente em termos de tratamento.

Os valores encontrados podem estar associados a um aporte relativamente mais reduzido de matéria orgânica do solo sob a área de Cerrado Sensu Stricto se comparado a fitofisionomia de Cerradão, o que pode ter influenciado a estruturação dos agregados deste solo (Figura 7). Ademais, a região apresenta variações quanto aos tipos de solo presente, podendo este apresentar uma maior concentração de areia em detrimento aos solos de Cerradão o que pode ter contribuído para um maior adensamento. Braz (2013) aponta que quanto mais elevada for à quantidade de areia de um solo maior será a sua densidade, considerando o fato de que presença significativa de areia, quando associada a baixos níveis de matéria orgânica do solo, proporciona uma menor predisposição para a formação de agregados, reduzindo a porosidade total e promovendo uma maior densidade. 


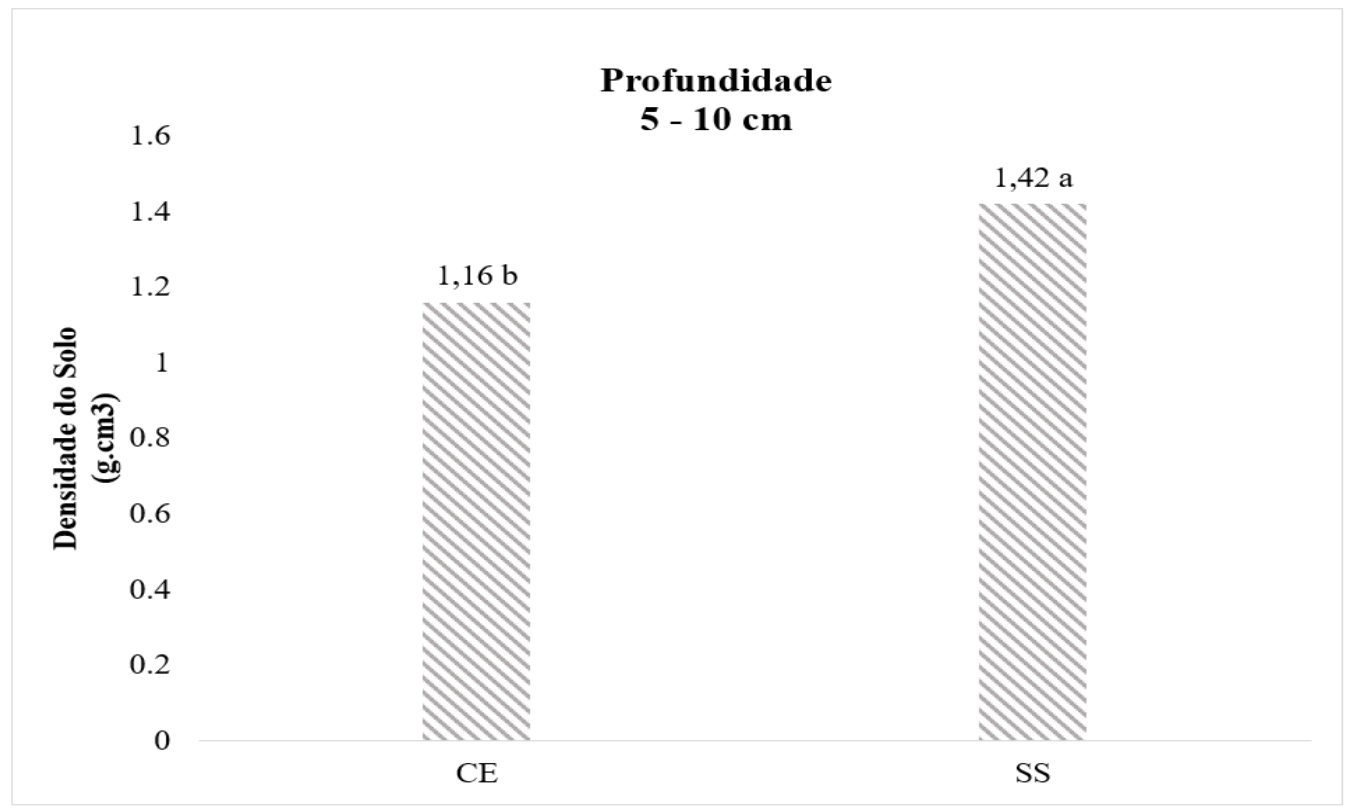

Figura 7. Densidade do solo sob diferentes fitofisionomias do Cerrado no PNNRP, em profundidade de $0.00-0.10 .{ }^{*}$ CE - Cerradão; SS - Sensu Stricto. *As médias seguidas pela mesma letra não diferem estatisticamente entre si pelo Teste de Tukey ao nível de $5 \%$ de probabilidade.

Destaca-se ainda que conforme os resultados verificados nas duas fitofisionomias quanto aos atributos físicos (umidade e densidade do solo) é possível observa uma relação direta destes atributos, tendo em vista que quanto maior for à densidade do solo menor serão os espaços porosos deste e consequentemente a presença de água no solo será reduzida (Figura 6). Neste contexto, Vicente et al. (2012) afirmam que com o aumento da densidade, a disponibilidade de água para o perfil do solo tende a diminuir mostrando uma provável compactação e provável redução dos espaços porosos.

\section{Conclusões}

Os solos das fitofisionomias de Cerrado sensu stricto e Cerradão apresentam-se naturalmente ácidos $\mathrm{e}$ com baixo nível de fertilidade, decorrentes do elevado nível de $\mathrm{pH}$ e reduzida concentração das bases trocais.

As riquezas de nutrientes nas fitofisionomias de Cerrado em estudo se mostraram reduzida proveniente da baixa disponibilidade de nutrientes, sendo a fitofisionomias de Cerradão portadora das maiores concentrações de $\mathrm{SB}$, CTC T e CTC $t$, assim como significativa concentração de COT e NT, e reduzida concentração de P disponível.

A fitofisionomia de Cerradão apresentou uma maior capacidade de armazenamento de água no solo, com maiores percentuais de umidade do solo, enquanto a fitofisionomia de Cerrado Sensu Stricto apresentou um maior nível de adensamento do solo.

As condições químicas e físicas do solo se mostram típicas de solos de Cerrado com seu nível de equilíbrio decorrente da dinâmica dos processos de elementos do solo atuante em áreas naturais. 


\section{Agradecimento}

Os autores gostariam de expressar a gratidão ao Instituto Chico Mendes de Conservação da Biodiversidade (ICMBio) pela outorga da Autorização para Atividades com Finalidade Científica no 52256-1, vinculada ao Sistema de Autorização e Informação em Biodiversidade (SISBIO), sem a qual esta pesquisa não poderia ter sido realizada.

\section{Conflito de interesses}

Os autores declaram não haver conflito de interesses.

\section{Referências}

Aerts, R. Climate, leaf litter chemistry and leaf litter decomposition in terrestrial ecosystems: A triangular relationship. Oikos, v. 79 , p. 439-449, 1997. https://doi.org/ $10.2307 / 3546886$

Araújo, R.; Goedert, W. J.; Lacerda, M. P. C. Qualidade de um solo sob diferentes usos e sob cerrado nativo. Revista Brasileira de Ciência do Solo, v. 31, p. 1099-1108, 2007. https://doi.org/10.1590/S0100-06832007 000500025

Braz, R. S. Qualidade da solo medida por indicadores físicos em área com aplicação de resíduo de caju. Fortaleza: Universidade Federal do Ceará, 2013. (Dissertação de mestrado). Disponível em: <http://www.ppgsolos.ufc.br/images/Dis_Re g_San_Braz.pdf>. Acesso em: 2 jan. 2018.

Bremner, J. M.; Mulvaney, C. S. Nitrogen total. In: Page, A. L.; Miller, R. H.; Keeney, D. R. (Eds.). Methods of soil analysis: Chemical and microbiological properties. 2. ed. Madison: American Society of Agronomy, 1982. v. 2. p. 595-624.

Cardoso, E. L.; Silva, M. L. N.; Curi, N.; Ferreira, M. M.; Freitas, D. A. F. Qualidade química e física do solo sob vegetação arbórea nativa e pastagens no Pantanal Sul-Mato-Grossense. Revista Brasileira de Ciência do Solo, v. 35, n. 2, p.613-622, 2009. https://doi.org/ 10.1590/S0100-06832011000200030
Carvalho, A. J. A.; Souza, E. H.; Marques, C. T. S.; Gama, E. V. S.; Nacif, P. G. S. Caracterização física dos solos dos quintais agroflorestais e cultivos monotípicos na Região de Amargosa, Bahia. Revista Brasileira de Agroecologia, v. 2, n. 2, p. 941-944, 2007. Disponível em: <http://revistas.aba-agroecologia.org.br/ index.php/rbagroecologia/article/view/703 0>. Acesso em: 2 jan. 2018.

Có Junior, C. Matéria orgânica, capacidade de troca catiônica e acidez potencial no solo com dezoito cultivares de cana-deaçúcar. São Paulo: Universidade Estadual Paulista, 2011. (Tese de doutorado).

Conservation International. Biodiversity hotspots. 2005. Disponível em: <https://www.conservation.org/How/Pages /Hotspots.aspx>. Acesso em: 27 jan. 2018.

Côrrea Neto, T. A.; Anjos, L. H. C.; Pereira, M. G.; Amorim, H. B.; Jaccoud, C. F. S. Atributos edafoambientais e parâmetros dendrométricos de plantios de eucalipto em uma topossequência no campus da UFRRJ, Seropédica (RJ). Revista Ciência Florestal,

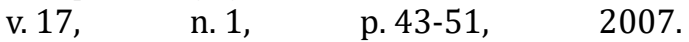
https://doi.org/10.5902/198050981934

Cunha, T. J. F.; Macedo, J. R.; Ribeiro, L. P.; Palmieri, F.; Freitas, P. L.; Aguiar, A. C. Impacto do manejo convencional sobre propriedades físicas e substâncias húmicas de solos sob Cerrado. Ciência Rural, v. 31, n. 1, p. 27-36, 2001. http://doi.org/10.1590/ S0103-84782001000100005

Doran, J. W.; Parkin, T. B. Defining and assessing soil quality. In: Doran, J. W. Coleman, D. C.; Bezdicek, D. F.; Stewart, B. A. Defining soil quality for a sustainable environment. Madison: Soil Science Society of America, $1994 . \quad$ p. 3-21. https://doi.org/10.2136/sssaspecpub35.c1

EMBRAPA - Empresa Brasileira de Pesquisa Agropecuária. Centro Nacional de Pesquisa de Solos. Manual de métodos de análise de solo. Rio de Janeiro: EMBRAPA, 1997.

FURPA. Zoneamento Ambiental das APA'S Serra da Tabatinga e Chapada das Mangabeiras nos Estados de Tocantins, Maranhão e Piauí. Teresina: FURPA, 1997. (Relatório).

Gregorich, E. G. Quality. In: Lal, R. Enciclopedia of soil science. New York: Marcl Dekker, 2002. p. 1058-1061. 
Jakelaitis, A.; Silva, A. A.; Santos, J. B.; Vivian, R. Qualidade da camada superficial de solo sob mata, pastagens e áreas cultivadas. Pesquisa Agropecuária Tropical, v. 38, n. 2, p.118-127, 2008. Disponível em: <https://www.revistas.ufg.br/pat/article/vie w/4171/3665>. Acesso em: 27 jan. 2018.

Kiehl, E. J. Manual de Edafologia: relação solo-planta. São Paulo: Agronômica Ceres, 1979.

Kolm, L. Ciclagem de nutrientes e variações do microclima em plantações de Eucalyptus grandis Hill ex Maiden manejadas através de debates progressivos. Piracicaba: Universidade de São Paulo, 2001. (Dissertação de mestrado).

Larson, W. E.; Pierce, F. J. The dynamics of soil quality as a measure of sustainable management. In: Doran, J. W.; Coleman, D. C.; Bezdicek, D. F.; Stewart, B. A. (Eds.). Defining soil quality for a sustainable environment. Madison: Soil Science Society of America, 1994. p.37-51. (SSSA Special Publication, 35).

Lima, M. G. M. Mamíferos de médio e grande porte do Parque Nacional das Nascentes do Rio Parnaíba, Brasil. Belém: Universidade Federal do Pará, 2009. (Dissertação de mestrado).

Lopes, A. S.; Cox, F. R. A survey of the fertility status of surface soils under "cerrado" vegetation in Brazil. Soil Science Society of America Journal, v. 41, n. 4, p. 742-747, 1977. https://doi.org/10.2136/sssaj1977. 03615995004100040026x

Lovato, T. Mielniczuk, J.; Bayer, C.; Vezzani, F. Adição de carbono e nitrogênio e sua relação com os estoques no solo e com o rendimento do milho em sistemas de manejo. Revista Brasileira de Ciência do Solo, v. 28, n. 1, p. 175-187, 2004. https://doi.org/10.1590/S010006832004000100017

Machado, R. B.; Ramos Neto, M, B.; Pereira, P. G. P.; Caldas, E. F.; Gonçalves, D. A.; Santos, N. S.; Tabor, K.; Steininger, M. Estimativa de perdas da área do Cerrado brasileiro. Brasília: Conservation International do Brasil, 2004. (Relatório). Disponível em: <http://cmbbc.cpac.embrapa.br/RelatDesma tamCerrado CIBrasil JUL2004.pdf>. Acesso em: 27 jan. 2018.
Martins Jr., O.P.; Chaves, F. Uso de instrumentos econômicos para a conservação da biodiversidade em Goiás: reserva legal, servidão florestal e bolsa de reserva florestal. In: Ferreira, L. G. (Org.). Conservação da biodiversidade e sustentabilidade ambiental em Goiás: prioridades, estratégias e perspectivas. Goiânia: SEMARH/AGMA/World Bank, 2006. p. 165-175.

MMA - Ministério do Meio Ambiente. Plano operativo de prevenção e combate aos incêndios florestais do Parque Nacional das Nascentes do Rio Parnaíba. Corrente: MMA, 2007. Disponível em: <http://www.ibama.gov.br/phocadownload/ prevfogo/planos_operativos/37-

parque_nacional_nascentes_rio_parnaibapi.pdf>. Acesso em: 14 jan. 2017.

Neves Neto, D. N.; Santos, A. C.; Santos, P. M.; Melo, J. C.; Santos, J. S. Análise espacial de atributos do solo e cobertura vegetal em diferentes condições de pastagem. Revista Brasileira de Engenharia Agrícola e Ambiental, v. 17, n. 9, p. 995-1004, 2013. https://doi.org/10.1590/S1415-43662013 000900013

Oliveira, M. E. A. Mapeamento, florística e estrutura da transição campo-floresta na vegetação (Cerrado) do Parque Nacional e Sete Cidades, Nordeste do Brasil. São Paulo: UNICAM, 2004. (Tese de doutorado)

Ramos, F. O.; Sousa, I. C.; Barros, L. C.; Sousa, V. F. Avaliação da fertilidade dos solos em áreas preservadas e degradadas as margens do Córrego Machado no Município de Palmas-To. Palmas: UBEC, Católica do Tocantins, 2017. (Monografia).

Santos, M. P. D. Composição de avifauna nas áreas de proteção ambiental Serra da Tabatinga e Chapada das Mangabeiras, Brasil. Boletim do Museu Paraense Emílio Goeldi, v. 17, n. 1, p. 43-67, 2001.

Streck, C. A. Índice $\mathbf{S}$ e fluxo de água e ar em solos do sul do Brasil. Santa Maria: Universidade Federal de Santa Maria, 2007. (Tese de doutorado).

Teodoro, D. A. A. Biomassa, estoque de carbono e nutrientes no Cerrado. Brasília: UNB, 2014. (Dissertação de mestrado).

Vicente, T. F. S.; Pedrosa, E. M. R.; Rolim, M. M.; Oliveira, V. S.; Oliveira, A. K. S.; Souza, A. M. P. L. Relações de atributos do solo e 
estabilidade de agregados em canaviais com e sem vinhaça. Revista Brasileira de Engenharia Agrícola e Ambiental, v. 16, n. 11, p. 1215-1222, 2012. https://doi.org/ 10.1590/S1415-43662012001100010

Yeomans, J. C.; Bremner, J. M. A rapid and precise method for routine determimation of organic carbon in soil. Communications in Soil Science Plant Analysis, v. 19, p. 14671476, 1988. https://doi.org/10.1080/0010 3628809368027 